\title{
CRISIS ECONÓMICA Y RETORNO A LAACTIVIDAD AGRÍCOLA EN CANARIAS
}

\author{
Carlos Santiago Martín Fernández \\ Víctor O. Martín Martín \\ Departamento de Geografía. Universidad de La Laguna \\ csmartin@ull.es, vbmartin@ull.es
}

\section{RESUMEN}

La crisis y la pérdida de activos en subsectores como la construcción y otros asociados a los servicios, ha propiciado el retorno e incorporación de muchos trabajadores a la actividad primaria. Un regreso que se lleva a cabo fundamentalmente fuera del sistema de control oficial, convirtiéndose en una práctica irregular que sostiene muchos hogares canarios. La Administración, para evitar esta situación, ha llevado a cabo medidas como los bancos de tierras y los huertos urbanos, que solo han supuesto una solución parcial a las pobres economías familiares.

Palabras clave: Crisis económica, actividad agrícola, economía sumergida, multifuncionalidad, bancos de tierra, huertos urbanos, Islas Canarias.

\begin{abstract}
The crisis and the loss of population activates in subsectors as the construction and other partners to the services, has propitiated the return and incorporation of many workers to the primary activity. This return is carried out fundamentally out of the system of official control, turning into an economic irregular activity that nowadays it supports to many homes. The Administration, to avoid this situation, has carried out measures like the banks of lands and the urban gardens, which alone have supposed a partial solution to the poor familiar economies.
\end{abstract}

Keywords: economic crisis, agricultural activity, irregular economy, multifunctionality, banks of land, urban gardens, Canary Islands.

Fecha de recepción: diciembre 2013.

Fecha de aceptación: mayo 2014. 


\section{INTRODUCCIÓN}

La crisis económica y el incremento en las cifras del paro han generado en las Islas una progresiva recuperación de algunas tierras agrícolas para el autoconsumo y comercialización marginal. Muchas personas han decidido replantar sus propiedades, ampliarlas o incorporarse sin tierras propias a la actividad primaria, en un intento de paliar los duros efectos de la crisis.

Este fenómeno, confirmado por las autoridades insulares y regionales, presenta por sus especiales características, notables problemas cuantitativos, hasta el punto que, aun reconociendo el fenómeno, las administraciones son incapaces de aportar cifras concretas sobre este crecimiento. Tenemos, entonces, un problema de fuentes, que viene a insistir en la ya de por sí problemática participación estadística de los activos agrarios en el mercado de trabajo en Canarias.

No cabe duda de que el papel del sector primario en Canarias es más amplio y complejo de lo recogido estadísticamente ${ }^{1}$. A menudo, los recuentos no valoran convenientemente el peso de la agricultura como actividad secundaria (agricultura a tiempo parcial), tampoco recogen la importancia que en la actualidad tiene como actividad principal para muchos oficialmente reconocidos como parados, así como el papel que tienen los no activos, que, aunque oficialmente así reconocidos, son trabajadores reales en la agricultura.

Todos estos inconvenientes nos han llevado a construir el presente trabajo sobre fuentes cualitativas, como la prensa y las entrevistas en el campo, una metodología que no solo nos permitió constatar la existencia de un repunte de la actividad agraria, sino que además sirvió para caracterizar este proceso como una forma peculiar de adaptación a una particular estructura y coyuntura económicas.

\section{PANORAMA GENERAL DE LA ACTIVIDAD AGRÍCOLA EN CANARIAS}

En Canarias, es preciso diferenciar dos modalidades agrarias. La que produce para el mercado exterior, en regadío, localizada en la franja costera entre el nivel del mar y la cota 300 metros, altamente tecnificada y organizada, donde los grandes propietarios y sectores pujantes de la burguesía agraria juegan un papel determinante, posee rendimientos económicos considerables y se produce para la exportación. Siendo por ello comercialmente sensible a las negociaciones en el marco de la Organización Mundial del Comercio y los tratados preferenciales de la Unión Europea.

Y un segundo tipo, la agricultura que produce para el mercado interior, en competencia con los productos importados, o para el autoconsumo familiar. Localizada en las denominadas «medianías» insulares (entre los 400-1000 metros de altura en las vertientes septentrionales y algo más altas en las meridionales), preponderantemente de secano, pobremente tecnificada y organizada, está constituida por explotaciones minifundistas y tiene una dedicación, preferentemente a tiempo parcial como complemento a otras actividades no agrícolas.

1 Según el Servicio Canario de Empleo (Gobierno de Canarias), el sector agrícola en las islas ocupa a unas 26.000 personas, el 3,3 por ciento del total de ocupados del Archipiélago. 
El primer tipo de agricultura se caracteriza por los monocultivos en regadío, con especial incidencia del plátano, el tomate, la flor cortada ornamental y esqueje, el pepino y los pimientos, estos últimos en contracción. Mientras que la agricultura de «medianías» tiene una producción más variada y limitada (policultivo), con los tubérculos (entre los que destaca la papa), los frutales (especialmente el viñedo para su transformación en vino), las leguminosas, los cítricos y las hortalizas, como sus producciones más significativas ${ }^{2}$.

Ambas tipologías en su conjunto, antaño apartado importante de la estructura económica canaria, a partir de la década de los años sesenta del siglo veinte, coincidiendo con el basculamiento de la actividad económica canaria hacia el sector servicios, comienzan una continua crisis. El cambio socieconómico en esa década se concreta en un importante trasvase de población del campo a la ciudad, que, unido a cambios en la estructura organizativa del trabajo y la irrupción de nuevas ofertas laborales en el sector servicios, acabaron provocando una reducción cuantitativa de los activos agrarios en el contexto general de la economía canaria.

Esta situación, que afectó a la totalidad del agro canario, presentó diferencias notables entre las dos modalidades agrícolas, siendo especialmente destacable en la actividad orientada al autoabastecimiento, mientras que la modalidad comercial, beneficiada en las ayudas ${ }^{3}$, en los procesos de reconversión y en la introducción de cultivos alternativos, aún en crisis, mantuvo un relativo peso económico, laboral y territorial en algunas islas y zonas.

Con todo, de una situación para la década de los años cincuenta en que el sector primario absorbía casi el 40 por ciento de la población activa y englobaba un tercio del Producto Interior Bruto (Hernández y Rodríguez, 1992:126), se ha pasado en la actualidad a concentrar el 3,3\% de los activos y englobar el 1,1\% del Producto Interior Bruto, muy lejos del 76,4 \% que corresponde al principal motor de la economía canaria, el sector servicios.

En paralelo a esta reducción en el peso económico del sector primario, se produce la pérdida de los espacios en los que éste se desarrollaba. El abandono ocupa ya más de 93.000 has. y supone el 12,5\% de la superficie del Archipiélago (García y Pestana, 2010:22). Una situación que, en un contexto de terciarización, ha incrementado las posibilidades de transformación y ocupación urbanística (turística, residencial o industrial) de las áreas agrícolas, ha supuesto la pérdida de capacidad para producir alimentos, destruido el patrimonio agro-

2 Recientemente se ha introducido, en distintos ámbitos espaciales de Canarias, una modalidad agrícola dedicada al abastecimiento de algunas cadenas comerciales: Mercadona, Hiperdino, etc.

3 Las ayudas agrarias se concretan en el Programa de Opciones Específicas por la Lejanía y la Insularidad (POSEI) de la Unión Europea, que aporta a esta región 268,4 millones de euros anuales desde el año 2008. El POSEI tiene dos apartados: el Régimen Específico de Abastecimientos (REA) y las ayudas a la producción local. Para el primer aspecto, el programa incluye unos polémicos 68,6 millones para un sistema de ayudas a la introducción y exención de impuestos a la importación de productos alimenticios de primera necesidad y materias primas para la industria agroalimentaria, que tratan de compensar los costes de transporte debido a la lejanía e insularidad del archipiélago canario. El REA tiene enfrentados a parte del sector agrícola y ganadero canario por su incidencia en la comercialización, no pudiendo competir en precios las producciones canarias en el mercado interior con alimentos importados, que se producen de manera más intensiva y competitiva que los producidos en las islas y que además tienen el coste del transporte al Archipiélago subvencionado. De momento, la posición de los importadores, apoyada en la defensa del consumidor isleño, ha tenido más peso que la ejercida por el sector productor de las Islas.

La otra gran línea del POSEI es el Programa de Apoyo a la Producción Local, con escasa importancia para la producción para el mercado interior, pues de los aproximadamente 200 millones de su ficha financiera, una cantidad superior a los 140 millones se destinan a ayudar a los productores de plátanos. 
pecuario, además de generar unas aceleradas consecuencias ambientales: deterioro de las condiciones edáficas por la aceleración de procesos erosivos, merma de acuíferos y manantiales, etc.

Aun con diferencias destacables para ambas tipologías agrícolas, podríamos decir que, en su conjunto, la agricultura en Canarias presenta dos grupos de condicionantes que se han acentuado con la crisis.

En la esfera de la producción, estaría la escasez de superficie agraria útil y la disponibilidad de recursos hídricos. Estos aspectos, tradicionalmente minimizados por medio de la inversión en tecnología (sorribas, enarenados artificiales, invernaderos, riegos localizados, desalación y depuración, etc.), entran en crisis cuando el capital reduce notablemente la inversión en estos factores, por competencia con otros usos, especialmente con la construcción y los servicios.

El otro condicionante es el comercial, que para el caso de la agricultura de autoabastecimiento o de mercado interior, se caracteriza por la existencia de un marco legal con régimen de ventajas a la importación ${ }^{4}$, así como en una diferencia abismal, por intermediación, entre el precio al que los agricultores venden y el precio de venta al consumidor ${ }^{5}$. Por su parte, el principal problema comercial para la agricultura de exportación, viene impuesto por la creciente competitividad de producciones de otros espacios con ventajas naturales y laborales más atrayentes que las existentes en el Archipiélago ${ }^{6}$.

De esta forma, el sector agrario que históricamente había desempeñado un importante papel en la economía canaria, desde la segunda mitad del siglo pasado ve como pierde protagonismo tanto en renta producida como en empleo generado y en hectáreas cultivadas, en beneficio del sector terciario y la construcción, que pasaron a partir de la década de los años setenta a ser los sectores dominantes en la economía canaria.

4 Las importaciones de productos agrícolas y ganaderos, muchos de ellos subvencionados, constituyeron en 2006 el 27 por ciento de todas las importaciones canarias. En veinte años, prácticamente en todos los alimentos ha caído la cuota de producción local. Canarias presenta participaciones muy inferiores al nivel mínimo de autoabastecimiento aconsejado por la Organización de las Naciones Unidas para la Agricultura y la Alimentación (FAO), que estima que la seguridad alimentaria existe cuando las producciones autóctonas satisfacen, al menos, el 75 por ciento de la demanda. En 2006, el Archipiélago exportaba por valor de 129.000 millones de euros en alimentos. pero las importaciones alcanzaban los 928.000 millones de euros (La Opinión de Tenerife, 4/11/2007, p.57).

5 La diferencia entre lo que pagan los consumidores por los productos frescos agrícolas y lo que reciben los productores canarios alcanzó en junio el mayor valor de este año, de manera que los agricultores percibieron solamente el 22 por ciento del precio de venta al público, según datos de la COAG Canarias. Según la Organización agraria en el calabacín, la col, la judía verde o habichuela, el pepino, el tomate y la papa, lo recibido por el agricultor no cubre los costes de producción. En cuanto a los productos ganaderos el diferencial fue menor, y en el caso de la ternera el precio de destino se multiplicó por 3,52.

6 Extraordinariamente beneficiado por las ayudas europeas, el plátano mantiene estable su producción en los últimos años. Su pico lo alcanzó en 1980 con 488.310 toneladas, 91.802 más que en 2010 (396.508), según datos del Gobierno canario. De cualquier manera, desde 1960, la producción se mantiene por encima de las 300.000 toneladas. Asimismo, las plantaciones tomateras destacan por su importancia social y en puestos de trabajo, al ocupar a más de 15.000 personas en Gran Canaria, Tenerife y Fuerteventura, aparte otros empleos en industrias paralelas (fábrica de cartonaje, insecticidas, mallas, plástico). El hándicap del tomate canario ha sido la competencia de Almería y, sobre todo, de Marruecos, que produce en la misma época que las Islas y acude a los mismos mercados. La campaña canaria de 1995/96 alcanzó volúmenes históricos con 356.220 toneladas exportadas, pero en los últimos diez años se ha agravado su evolución. Canarias ha pasado de exportar 239.059 toneladas en la temporada 2001/02 a las 94.948 en 2011, el último dato del que disponemos. 


\section{LAS FORMAS DE PRODUCCIÓN DOMINANTES HASTA LA CRISIS}

La poca actividad agraria de abastecimiento existente presenta connotaciones especiales, vinculadas tanto a las características de las explotaciones como a la propia actividad agraria en sí y a las personas que se dedican a ella.

En el área de subsistencia, son muy pocas las empresas agrarias existentes y, en las contadas ocasiones en que estas aparecen, son pequeñas. A la cabeza de la explotación estaría un autónomo, un asalariado en otro sector o un empresario de otro ramo, que se dedica a esta actividad beneficiándose de las ayudas existentes o con una marcada actitud especulativa, explotando unos suelos que se mantienen en expectativas de transformación urbanística («barbecho urbano»).

Estas explotaciones cuentan, con frecuencia, con apoyo familiar y esporádicamente con activos en otros sectores (construcción, hostelería, servicio doméstico) o inactivos (estudiantes y amas de casa), que entran, eventualmente y no siempre bajo el amparo legal, a trabajar en la recolección, envasado o transformación del producto agrario. Hablamos, por tanto, de empleo estacional y malas condiciones laborales y salariales, soportados por una población rural e inmigrante en condiciones difícilmente aceptables. Una actividad que, por sus características, es tempranamente abandonada en épocas de auge económico.

Junto a este tipo de explotaciones, y como modalidad agrícola más desarrollada en las medianías, nos encontramos otra forma de labor que se lleva a cabo no como actividad principal, sino para mantener la tradición familiar, por relación sentimental con el agro o como hobby, la popularmente llamada «agricultura de fin de semana». Se dedica a esta tipología una población laboralmente vinculada a otra actividad, que acude al campo cuando su trabajo se lo permite, normalmente de avanzada edad ${ }^{7}$, y que cultiva una pequeña parcela de su propiedad con ayuda temporal, normalmente no remunerada, de familiares, amigos o vecinos (ACIPMAGA, 2009 y Godenau, Suárez y Febles, 2009).

Por último, otra forma de trabajo es la que se realiza siguiendo formas de tenencia contractuales (medianería y aparcerías), entre un propietario absentista que arrienda y pone la tierra y un arrendatario o medianero, trabajador sin tierras o de una pequeña propiedad, que pone el trabajo en su totalidad. Entre ambos se reparten, según fórmulas acordadas, los costes y los beneficios del cultivo. Por sus características presenta una situación semejante que la primera modalidad comentada, es decir, malas condiciones laborales, escasos rendimientos y abandono creciente ${ }^{8}$.

7 «Yo a esto me dedico en mis ratos libres cuando no trabajo, porque me entretiene mucho, pero no como actividad profesional porque de esto ya no se puede vivir. Lo que cultivo es para consumo familiar, nada más... las faenas del campo han quedado para nosotros los viejos, los jóvenes ya no quieren saber nada de agricultura. ¡Y con razón! En cualquier empleo relacionado con el turismo ganan mucho más dinero trabajando muchísimo menos. El campo es muy duro y requiere mucho esfuerzo para muy pocos beneficios, y la verdad es que tenemos muy pocas ayudas. Es normal que se le quiten las ganas. Esto es para los que ya estamos acostumbrados porque lo hemos hecho toda la vida... Lo cierto es que cada vez hay menos agricultores pero es que no tenemos respaldos suficientes y es que no se entiende por qué se subvenciona el kilo de plátanos y no hay ayudas para las cebollas o las papas. No hay subvenciones y, cuando las dan, se eternizan en pagar, pero eso sí para pagar tasas o impuestos no tardan. Si hasta tenemos problemas para recoger la cosecha porque si contratamos a cuatro braceros para que nos ayuden por horas tenemos que hacerles un seguro, y claro no hay dinero... De esas cosas debería ocuparse la Administración, pero como nadie se ocupa las consecuencias pasan por un campo abandonado». (Lancelot, 7/11/2001, p. 50).

8 Estas modalidades, con algunas modificaciones específicas, también se producen en los cultivos de exportación. 


\section{EL ENFOQUE PRODUCTIVO PARA EL ABASTECIMIENTO EN CANARIAS CON ANTERIORI- DAD A LA CRISIS}

Las áreas agrícolas de abastecimiento y el espacio productivo donde éstas se insertan no recibían, antes de la actual crisis económica, su consideración estricta de actividades y espacios proveedores de alimentos. Esta utilidad, dentro de los esquemas de la multifuncionalidad del medio rural (Perdomo y Hernández, 2003; García, 2002, García, 2009 y Segrelles y Vásquez, 2012), era una más entre otras funciones, como la defensa del paisaje y el entorno, la asimilación como espacio para la producción de actividades de tipo turístico o deportivo, etc.

Entre el año 2000 y 2008, fecha considerada como el inicio de la actual crisis económica, las soluciones vertidas para afrontar el abandono del campo descansaban, de una parte, en la repoblación forestal, vinculada a la preocupación creciente por los efectos de los cada vez más frecuentes y destructivos incendios forestales; y de otra, en contadas políticas de financiación de la actividad agraria como productora de paisaje o de lucha contra la erosión.

Para el desarrollo de la primera opción, fue decisivo el incendio acontecido en el año 2000 en la isla de La Palma, en el que se reconoce oficialmente, por primera vez, que su rápida propagación se debió «a que algunos viñedos quemados tenían una atención muy pobre, puesto que estaban llenos de matorrales... el abandono del campo convierte a estas tierras descuidadas en un elemento importante de paso e intensificación de los incendios; lógicamente esta situación sería muy diferente si los campos estuvieran atendidos» (La Opinión, 3/08/2000, p. 27).

Este argumento se repetirá de forma constante a partir de este año. Por ejemplo, en el incendio en Los Campeches (Los Realejos- Tenerife), del que años después se dijo que «con toda seguridad no se hubiera producido si los campesinos de la zona hubieran sembrado papas en el invierno pasado en las mismas tierras que fueron colonizadas por matorrales, uno de los mejores combustibles para la aparición de conatos... las escasas tierras sembradas en esta zona ayudaron a controlar el avance del fuego, actuando de improvisados cortafuegos» (El Día, 25/09/2005, p. 18).

La solución al abandono, ante el riesgo de proliferación de incendios, fue ayudar para que las tierras se cultivaran ${ }^{9}$, la reforestación como medida de prevención ${ }^{10}$ u obligar a los propietarios de tierras agrícolas que no estuvieran cultivadas a limpiarlas o ararlas.

Son contadas las experiencias que promueven la generación de alimentos. Una de las excepciones, en esta etapa previa a la crisis, fue el caso de la repoblación o plantación en terrenos abandonados en Valleseco (Gran Canaria), en el que los propietarios cedían sus

9 Como, por ejemplo, la llevada a cabo en el municipio tinerfeño de Icod de los Vinos en 60 fincas, una iniciativa que consistía en poner a disposición de los propietarios de los terrenos maquinaria y personal, para habilitar las tierras a distintos cultivos (Diario de Avisos, 24/02/2002, p. 17).

10 En el año 2000, se reforestaron unas 150 hectáreas en Gran Canaria por la Fundación Canaria para la Repoblación (Foresta). Según esta Fundación, hacían falta más tierras y animaban a los agricultores que las tuviesen abandonadas a llamarlos para realizar con ellos proyectos de este tipo (La Tribuna de Canarias, 7/10/2000, p.14). Por su parte, el Cabildo Insular tinerfeño, como continuidad a la intensa campaña que venía ejecutando desde hacia una década, en el año 2000 reforestó 195 hectáreas de terreno repartidas en nueve parcelas de las medianías altas de los municipios sureños de Fasnia y Arico, con el objeto de regenerar tierras abandonadas de cultivo (Diario de Avisos, 3/11/2000, p. 10). 
fincas para destinarlas a la producción de manzanas a cambio de una parte de la producción (La Provincia 3/12/2009, p.10 y Canarias 7, 29/11/2009, p.38). O la propuesta, desestimada, del concejal de Izquierda Unida en el municipio de Los Realejos (Tenerife), de integrar en el Plan Insular de Ordenación (PIOT) la recuperación de «la actividad agropecuaria, volviendo a poner en explotación las tierras abandonadas y evitando de esa forma la ocupación del suelo agrícola con edificaciones» (Diario de Avisos, 13/12/2000, p.12).

También en Gran Canaria y desde el Cabildo Insular, se intentó a través de incentivos económicos animar a los propietarios a plantar sus fincas abandonadas con forrajeras. La propuesta de la Consejería de Agricultura y Ganadería destacaba que Gran Canaria era «alarmantemente deficitaria en la producción de forrajes [por lo que] en un contexto de alza mundial de los precios de los alimentos para el ganado no nos podemos permitir no aprovechar al máximo nuestra capacidad de producción» (Canarias 7, 4/10/2008, p.16).

La picaresca especulativa reinó en el desarrollo de esta iniciativa y así, a los datos inicialmente publicados de recuperación de casi 400 hectáreas de terrenos abandonados en distintos municipios de la Isla (La Provincia, 9/08/2009, p.9), hubo que realizar un importante recorte cuando se supo que los propietarios habían falseado los datos para cobrar fraudulentamente la subvención propuesta ${ }^{11}$ (Canarias 7, 20/10/2009, p.19).

En definitiva, entre el 2000 y 2008, no hay una apuesta manifiesta por producir alimentos. Las contadas propuestas para las áreas agrícolas de medianías se centran en apoyar la producción no de una necesaria cantidad de alimentos, sino una minoritaria calidad de alimentos (agricultura ecológica), mantener la actividad como una pervivencia cultural vinculada a los servicios (turismo rural), mantenerla como fundamento del paisaje tradicional de las Islas (espacios protegidos) y para el sostenimiento ecológico (lucha contra la erosión y los incendios).

\section{EL CAMPO REFUGIO EN SITUACIÓN DE CRISIS}

Esta situación cambia a partir del año 2008. La crisis económica que padecemos supuso el regreso al sector primario para muchas familias demandantes de alimentos ${ }^{12}$. Y así, esta rama de actividad en Canarias se encuentra en un proceso de reversión, lenta pero constante, que guarda relación directa con el crecimiento del número de parados que se han ido sumando en los últimos años a los listados oficiales de desempleados ${ }^{13}$.

11 Hubo casos en los que la superficie recuperada para el cultivo no llegó ni a una vigésima parte de los terrenos para los que se obtuvo la subvención (La Provincia, 12/10/2009, p. 14) De los 168 beneficiarios, 159 particulares y nueve empresas, 43 plantaron menos terreno del que declaraban, según las actas de inspección del Servicio de Extensión Agraria (Canarias 7, 29/11/2009, p. 38).

12 Según la Encuesta de Presupuestos Familiares 2012 del Instituto Nacional de Estadística (INE), el gasto medio por persona en alimentos y bebidas no alcohólicas supuso el 14,70 por ciento del total del gasto. En este porcentaje, destacan como consumos alimenticios principales los productos de la huerta: frutas frescas, con un 15,7 por ciento, y las hortalizas y papas, con un 12 por ciento (MINISTERIO DE AGRICULTURA, ALIMENTACIÓN Y MEDIO AMBIENTE, 2012).

13 Carmelo Santana, de 40 años, se dedicaba antes al sector de la construcción, pero, desde que éste se viniera «a pique», decidió que era mejor trasladarse a otra actividad. «Me tuve que ocupar en esto porque prácticamente no hay otra cosa», admite con resignación. «La situación de Canarias es un desastre»... Su salvación hasta ahora es lo que vende en diferentes mercadillos, «que es con lo que se va escapando más o menos» (La Provincia, 19/08/2012, p. 20). 
La vuelta al campo fue la primera opción para muchos desempleados canarios. Tras décadas de pérdidas de activos agrarios, Canarias fue la comunidad autónoma que registró el mayor aumento de ocupados en este sector en 2010 con respecto a 2009. En total, 606 nuevos trabajadores se incorporaron al sector primario, lo que se tradujo en una subida del 27 por ciento, según datos publicados por la Encuesta de Población Activa (EPA). De este modo, este sector se convirtió, en una situación de alta tasa de desempleo como la que se registra en Canarias, en cobijo para demandantes de empleo (COAG, 2010).

Figura 1

MACIZO DE ANAGA (EL BATÁN, LA LAGUNA, TENERIFE)

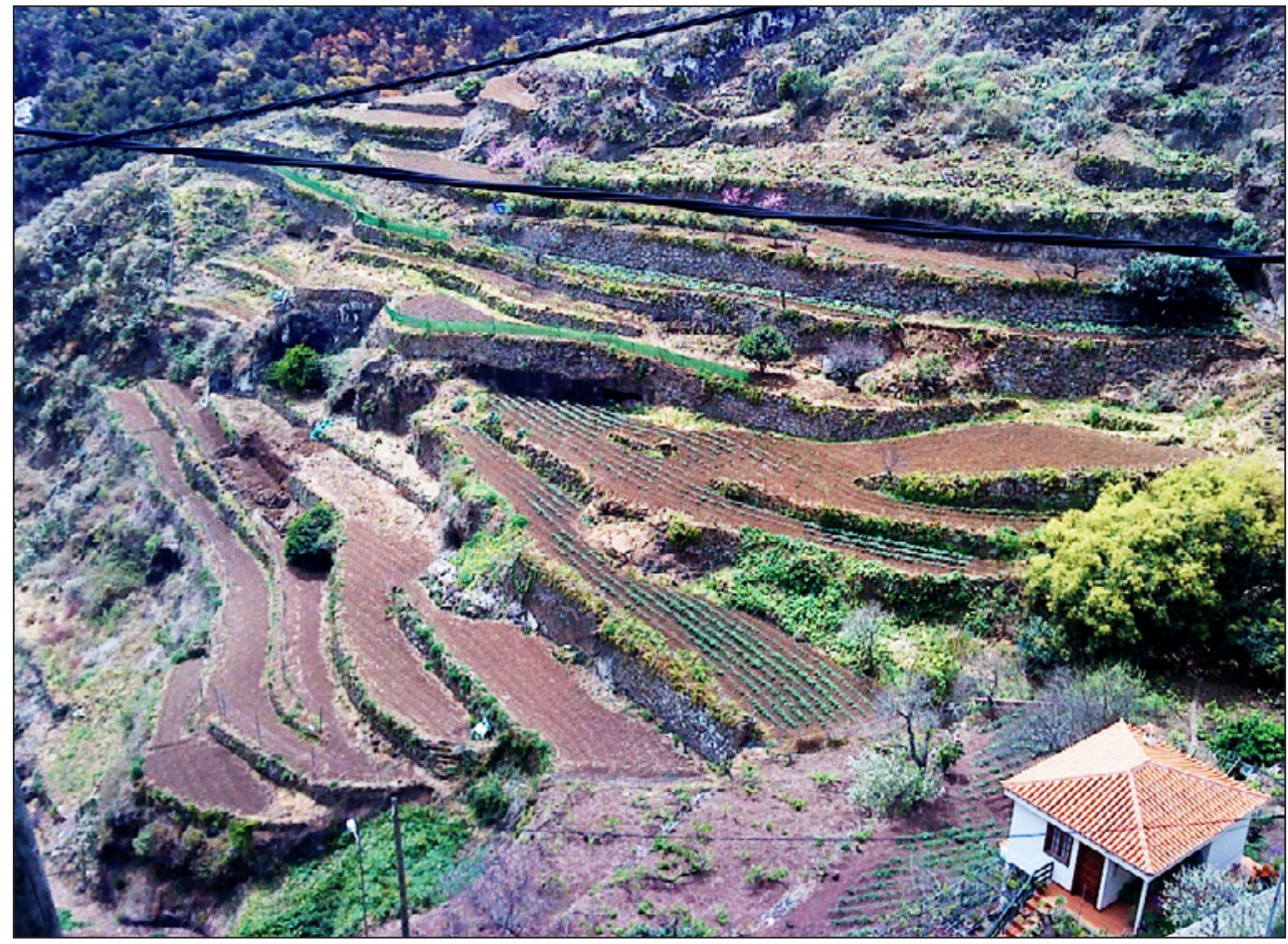

Fuente: Carlos S. Martín y Víctor O. Martín. Se observan pequeñas explotaciones agrarias recuperadas para la agricultura como consecuencia de la crisis económica en las montañas de este macizo antiguo. Se trata de cultivos de papas, hortalizas y frutales.

A estos datos habría que añadir la incorporación al campo de una gran cantidad de trabajadores no recogidos como nuevos activos, pues estos se mantienen en las listas como demandantes de empleo a la vez que cultivan fincas propias o arriendan tierras de otros ${ }^{14}$. El

14 En el trabajo de campo realizado en Tenerife y sureste de La Palma (23 entrevistas semiestructuradas, donde el entrevistado expresaba su punto de vista y hablaba con toda libertad), no encontramos ningún caso de alta como activo agrario, todos estaban en la economía sumergida. Algo que por otro lado no es de extrañar en una Comunidad Autónoma como la canaria, donde la economía sumergida es el 28 por ciento del Producto Interior Bruto (Canarias 7, 22/02/2013, p. 9). 
trabajo de campo realizado entre mayo y agosto de 2013 confirmó que el crecimiento ha sido constante y que la actividad productiva de subsistencia es muy superior a la registrada en las estadísticas oficiales.

La incorporación de estos nuevos activos a la agricultura se produce en dos fases. La primera acontece de forma inmediata a los primeros efectos de la crisis. Pronto, muchos trabajadores expulsados del binomio construcción-servicios, propietarios de tierras, acuden a estas o intensifican su contacto con las actividades agrarias. Unos incluso se dan de alta en la Seguridad Social (es el dato recogido por la COAG), pero la mayoría se limitarán a dedicar más tiempo a sus «explotaciones de fin de semana», que pasan ahora a ser más intensamente trabajadas. En esta fase, el objetivo es el autoconsumo, servir de complemento a los mecanismos de protección social (subsidios de paro y otras ayudas sociales), pues la mayoría consideraba que la crisis pasaría y que pronto volverían a sus ocupaciones principales. Esta fase dura poco tiempo, pues rápidamente se entra en una segunda, como consecuencia de la continuidad y profundización de la crisis.

La pérdida o reducción de los subsidios de paro y/o el incremento de las necesidades familiares por aumento del número de parados por unidad familiar obliga a modificar la estrategia, ampliándose la actividad agrícola desde la subsistencia al comercio de algunos excedentes cultivados para el mercado local, con la intención de compensar las pérdidas producidas por los recortes en las prestaciones sociales e intensificación de la crisis. «Antes, la mujer tenía aquí algunas lechugas, unos tomates, las papas y las gallinas, ahora hemos cogido los canteros de mi suegro y algunas viñas que estamos sacando adelante. Allí planto verduras que vendo como puedo. Saco algo» (Entrevista 2. La Matanza, Tenerife).

Buena parte de la actividad que acontece en esta fase (sobre todo la comercialización) se realiza fuera de los cauces administrativos y la intermediación legal ${ }^{15}$. Una opción que se lleva a cabo como un renglón más de la economía sumergida y que debe analizarse desde la óptica de la función costes y beneficios. Eludir las normas (fiscales, técnicas y laborales) supone una disminución en los costes y, por tanto, una mejora objetiva en términos de competitividad en un mercado de alimentos como el canario, en el que la fijación de los precios viene determinada por las importaciones de bajo coste y en el que estas relaciones comerciales irregulares cumplen la labor de enfriar el ánimo de un creciente número de consumidores en precaria situación económica. «Si pago todo lo que me piden trabajo para ellos, no me sirve» (Entrevista 4. La Matanza, Tenerife).

Escapar al control oficial posibilita además seguir cobrando prestaciones sociales, el paro o la ayuda extraordinaria de 400 euros, al mismo tiempo que se realiza la actividad agrícola. Esta renta, como hemos visto, resulta capital para el mantenimiento familiar.

15 Entre las entrevistas realizadas, sólo una explotación había legalizado (y no toda) su actividad. Además, existe un reconocimiento oficial sobre el tránsito de la subsistencia a la comercialización: «mientras que en 2010 y 2011 se apreció un regreso al mundo rural, pero con una vocación de autoconsumo, el cual no es el modelo que consideramos prioritario, el pasado año se empezó a notar que a medida que ha avanzado la crisis ha despertado el interés de muchas personas a llevar a cabo proyectos empresariales del sector primario», indicó el consejero de agricultura del Cabildo Insular José Joaquín Bethencourt (Diario de Avisos, 9/03/2013, p. 26). 
Los mecanismos por los que se elude la legalidad son múltiples, pero en líneas generales es dominante la salida de estos nuevos productores de los cauces comerciales regulares, comenzando ellos mismos a vender sus producciones en su casa, hogar por hogar, al borde de las carreteras, a determinadas fruterías al contado, etc. Más adelante expondremos dos ejemplos claros de esta nueva situación comercial.

\section{LA ADMINISTRACIÓN RECONOCE EL PROCESO PERO SIN APORTAR DATOS}

Sin entrar en detalles, por razones obvias, la administración confirma desde diferentes instancias el despegue de la actividad agrícola en el área de medianías. Así, el Consejero de Agricultura, Ganadería y Pesca del Cabildo de Gran Canaria, Rafael Álamo, señalaba la existencia de indicadores que lo probaban, como el caso de la extraordinaria actividad registrada este año en el Laboratorio Agroalimentario y Fitopatológico del Cabildo Insular de Gran Canaria, donde se hacen análisis del agua y tierra para la actividad primaria, «que está ahora a tope de trabajo» (Canarias 7, 28/08/2012, p. 16). O el consejero de Agricultura y Ganadería del Cabildo de Tenerife, José Joaquín Bethencourt, quien afirmaba que en la Isla se había detectado «un repunte de la agricultura de subsistencia», un aumento que provenía, en la mayoría de los casos, de personas que habían perdido su empleo en el sector de la construcción. Apuntaba además, que la zona donde más se apreciaba este fenómeno era en las «medianías», en tierras heredadas y no utilizadas, allí donde antaño se habían desarrollado prácticas vinculadas a la denominada agricultura de subsistencia (Diario de Avisos, 1/07/2009, p. 2).

A la pregunta sobre ¿Qué signos tenemos para defender la idea de que la agricultura de medianías se está recuperando?, Bethencourt señalaba: «a pesar de que se ha reducido la superficie cultivada, también se ha reducido el abandono. Esto quiere decir que la mayor amenaza que tiene el suelo cultivado no es el abandono, sino la presión de otros usos. Hay otros dos signos inequívocos de que las medianías de la Isla recuperan el pulso perdido, constatados por las Agencias de Extensión Agraria. El primero de ellos es que muchas pequeñas fincas, sobre todo en las medianías del Norte de la Isla, se están recuperando para el autoconsumo, debido a la situación de desempleo por la que atraviesan en estos momentos sus titulares, que las han puesto en explotación en la mayor parte de los casos pensando en el abastecimiento de la familia y, en otros, como generadora de renta complementaria. En esos casos, la recomendación que hace el Cabildo es incluir esos volúmenes de producción en los circuitos convencionales ya existentes, especialmente las cooperativas u organizaciones de productores» (El Día, 6/01/2010, p. 30).

También los sindicatos agrarios resaltan este incremento. Rafael Hernández, presidente de COAG-Canarias, explicaba este fenómeno de la siguiente forma: «en la medida que se acentúa la tasa de desempleo, la gente da vueltas para encontrar algo. Al no hacerlo, busca otras salidas y ante el batacazo de la construcción, muchas de esas personas han regresado al campo. Así, las familias con terrenos abandonados han decidido emprender un proyecto vital en el sector de la agricultura, en vez de estar cobrando del sistema» (La Provincia, 29/08/2011, p. 19-20).

Además, el regreso al campo es algo constatable paisajísticamente en zonas como las medianías del Norte de la isla de Tenerife. Azotadas por la crisis del subsector de la cons- 
trucción, los nuevos activos, antaño obreros de la construcción, ven ahora a la agricultura como un mecanismo de ingresos complementarios a la prestación por paro o la ayuda social, cuando no como su único medio de vida.

Figura 2

PAISAJE AGRARIO SEMIABANDONADO DE EL VALLE DE EL PALMAR, MUNICIPIO DE BUENAVISTA EN EL NORTE DE TENERIFE

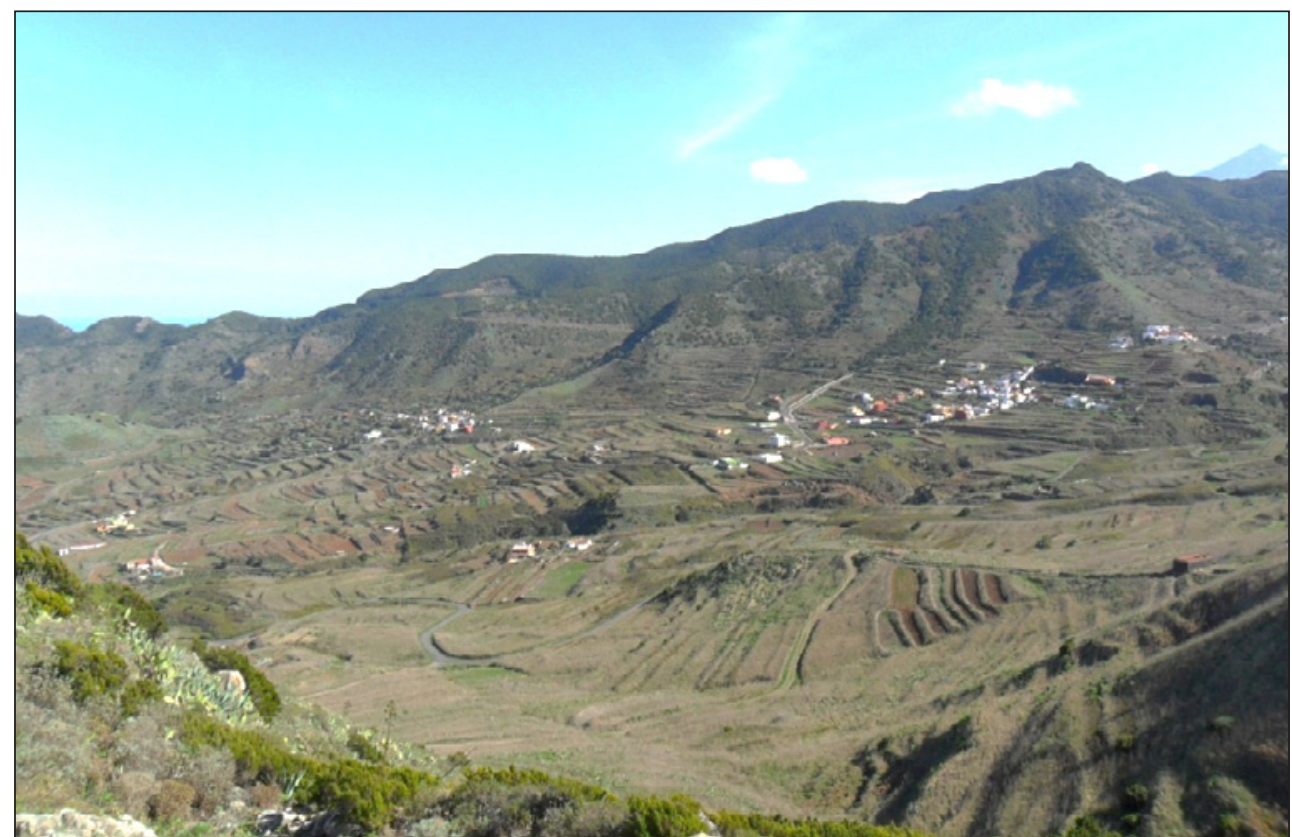

Fuente: Carlos S. Martín y Víctor O. Martín. Se puede observar, dentro del abandono generalizado de la agricultura de medianías dedicada al autoconsumo y mercado interior, la puesta en cultivo reciente de algunos pequeños huertos para el cultivo de la papa.

Un ejemplo de esta situación es el municipio de La Matanza de Acentejo (Tenerife) ${ }^{16}$. Según datos municipales, más del 50 por ciento de las tierras cultivadas son trabajadas por desempleados que siembran para el autoconsumo, principalmente papas. El concejal de Agricultura, Miguel Ángel Pérez, tiene claro el origen de la nueva coyuntura económica y laboral: «las personas que antes trabajaban en la construcción dedicaban los fines de semana a la agricultura temporal». Ahora, añade el edil, «las huertas que antes no se explotaban se cultivan para autoabastecimiento, más concretamente los llamados huertos caseros» (Diario de Avisos, 11/03/2013, p. 10).

16 Es este un municipio ejemplar. El análisis del Padrón Municipal del 2003 señalaba cómo la población activa agraria había disminuido notablemente, quedando reducida a la práctica de la agricultura a tiempo parcial, aunque destacaba la producción vitivinícola con excedentes comerciales dentro del propio ámbito municipal y también comarcal. Este descenso de la actividad agrícola estaba relacionado con el trasvase de la mano de obra hacia el sector secundario, sobre todo al subsector de la construcción, y al terciario, principalmente a los servicios en el área turística de Puerto de la Cruz, primero, y a los núcleos de la fachada suroccidental insular, después. 
Figura 3

SISTEMAAGRARIO DE CULTIVOS DE PAPAS ASOCIADO A CASTAÑOS, EN LA COMARCA DE ACENTEJO, NORTE DE TENERIFE

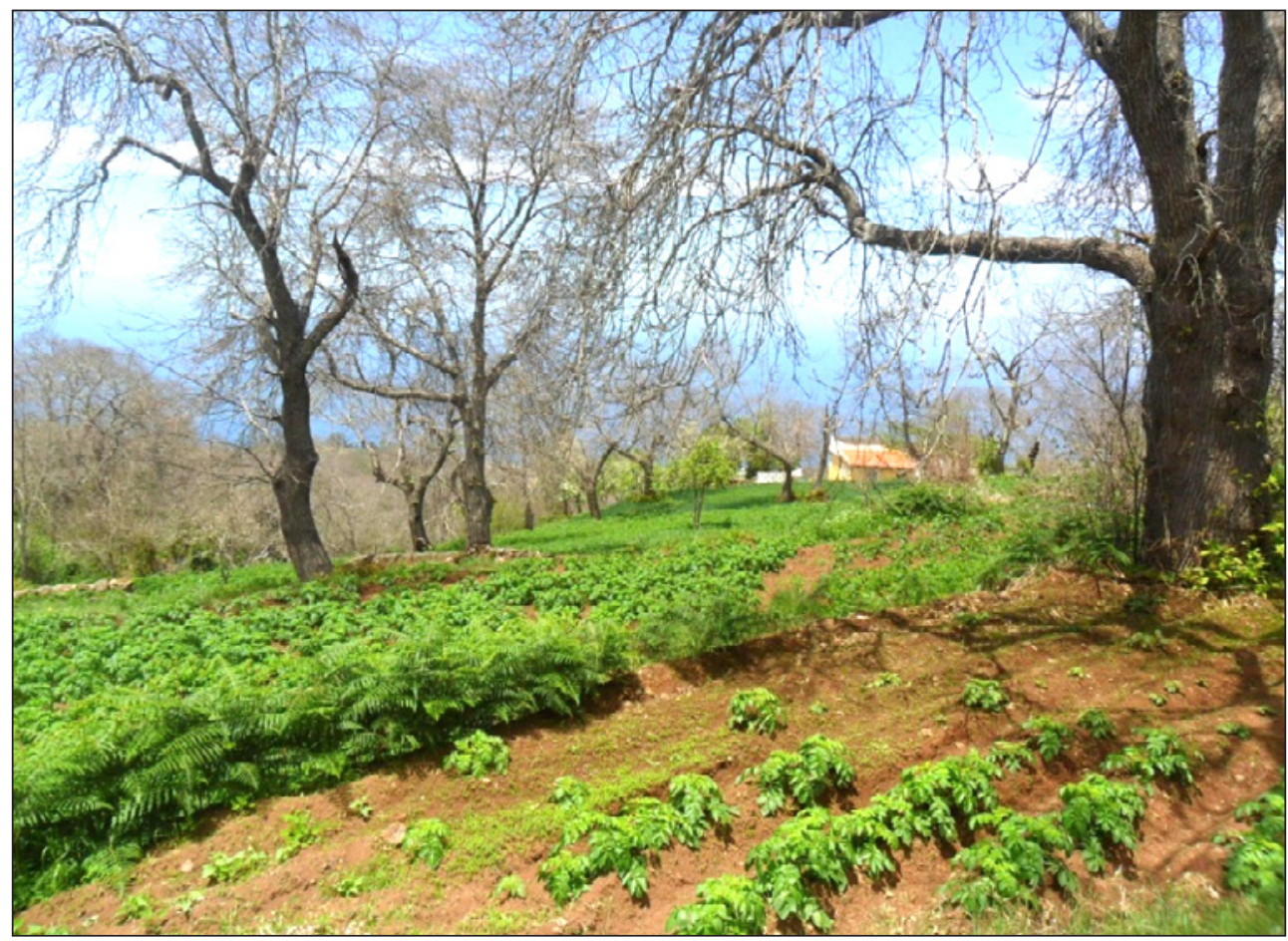

Fuente: Carlos S. Martín y Víctor O. Martín. Es esta una comarca representativa de la vuelta al campo y de la reactivación agrícola y del surgimiento de los «Guachinches». La crisis de la construcción de 2008 en adelante ha sumido a estos municipios en tasas de paro superiores al 50\%. Una salida ha sido, entonces esa vuelta al campo.

Por esta cuestión, no debemos hablar, en muchos casos, de regreso a la actividad agrícola, pues la mayoría de estos trabajadores nunca llegaron a abandonar definitivamente la agricultura, actividad que compaginaron a tiempo parcial con otra principal.

Pero estos no son los únicos. También existen muchos jóvenes desempleados con formación en otras disciplinas que toman la explotación de sus padres o abuelos ${ }^{17} \mathrm{o}$ también mujeres (normalmente amas de casa) que, por la gravedad de la situación económica, trabajan

17 Hasta hace poco tiempo, Alfredo Falcón se ganaba la vida por medio de la construcción. Sin embargo, desde que comenzara la crisis ha tenido que volver a sus orígenes para buscarse «una salida» que le permite «poder seguir viviendo y escapar», aunque piensa que este sector «no tiene mucho futuro, tal y como están las cosas ahora». De hecho, señala un cercado de papas afirmando que no sabe «si merecerá la pena cogerlas o dejar que se pudran». A su juicio, existe «una diferencia abismal» entre el precio que se exige al consumidor y el dinero que cobran ellos por su trabajo. Por eso dice que no sabe «a lo que llegará esto». En las tierras que posee en El Faro, barrio de Teror (Gran Canaria), pasa unas 12 horas diarias con el único objetivo de «juntar los garbanzos para comer». Su hijo Ayoze Falcón, de 21 años, también está introduciéndose en el sector agrario. «Si mejorase la situación, me dedicaría a otro sector que fuese menos trabajoso que este», pero «tal y como está la cosa, pues es lo que más a mano tengo» (La Provincia, 19/08/2012, p. 20). 
los campos para completar una mermada renta familiar. Es decir, toda una serie de nuevos activos invisibles estadísticamente, que siempre han estado ahí, pero que ahora, por razón de la crisis, incrementan su número.

En algunas islas este proceso si que se hace visible en aumentos de la superficie cultivada. Así, el mapa de cultivos insular más actualizado es el de Gran Canaria ${ }^{18}$. Contamos con tres mapas de cultivos referidos a los años 2001, 2005 y 2013 en esta isla. Las comparaciones resultan difíciles en esos tres mapas. En primer lugar, la superficie agrícola total va de las 30.610 has en 2001 a 35.518 en 2005 y 32.546 en 2013. Esto significa que entre 2001 y 2005 aparecen como superficie agraria 4.908 has nuevas (período de desagrarización), un $16 \%$ más; mientras que entre 2005 y 2013 desaparecen del mapa de cultivos de la isla 2.972 has, lo que representa un $8,3 \%$ de superficie de cultivo desaparecida (ni siquiera aparece como superficie abandonada) (en un período de supuesta vuelta al campo). Todo esto nos habla de la necesaria crítica de las fuentes documentales para el trabajo que nos ocupa.

Si hablamos de superficie cultivada, ésta no ha hecho más que descender, pasando de las 13.547 has en 2001 a las 12.507 en 2008 y a las 11.884 en 2013. Existen algunos cultivos que ganan superficie, frente a otros que la pierden, resultando que en general entre ambas fechas se han dejado de cultivar 622 has.

Aun así, el mapa de cultivos de Gran Canaria aporta datos que confirman la tesis que se sostiene en este artículo, cuando analizados la evolución de la superficie de determinados cultivos que tienen que ver con la pequeña agricultura o agricultura familiar, es decir, de autoconsumo y/o mercado interior: las hortalizas (en las subcategorías de huerta limpia, huerto familiar y hortalizas) pasan de 3.198 a 3.593 has, aumentando en 395 has, y las papas pasan de 864 a 1.192 has, aumentando en 328 has.

Es ínfima la cantidad de nuevos activos que se incorporan a explotaciones agrícolas legales para el mercado interno o como obreros en las empresas agroexportadoras. Esta última situación ha sido uno de los argumentos que más ha contribuido a negar este repunte de la actividad agraria de subsistencia. Desde la patronal, Roberto Goiriz, portavoz de la Federación de Exportadores Hortofrutícolas de Las Palmas (FEDEX), quitó importancia a la recuperación, considerando que «los hechos demuestran que las expectativas de que la agricultura se convertiría en un sector refugio ante la pérdida de empleo por la crisis eran un deseo más que una realidad» (Canarias 7, 22/04/2011, p. 25).

En un tono menor, se expresó el presidente de la Asociación de Productores de Plátanos (ASPROCAN), Francisco Rodríguez, quien afirmó que el empleo en este subsector «ha aumentado algo», lo que confirma que la agricultura «sí ha servido de refugio para una parte de la población» (Canarias 7, 22/04/2011, p. 25).

Esta diferente opinión tiene que ver con las características, en algunas islas, de ambos cultivos de exportación. El plátano difiere del tomate en que en el primero aún existe una pequeña propiedad que funciona en términos laborales de una forma semejante a la agricultura de medianías: pobremente tecnificada, con una dedicación a tiempo parcial y que actúa como complemento a una actividad principal no agrícola. Estas fincas, al igual que en el área

18 http://www.gobcan.es/agricultura/temas/desarrollo_rural/mapacult/cambiogc.htm. 
de subsistencia, se convierten en refugio laboral en situación de crisis ${ }^{19}$. Una situación que no se manifiesta por igual en el tomate, controlado por grandes empresas productoras que contratan peones agrícolas, en muchos casos en situación de precariedad laboral.

\section{PROBLEMAS DE COMERCIALIZACIÓN: EL INCREMENTO DE GUACHINCHES Y LA VENTA AMBULANTE}

Ya comentamos cómo, en las medianías isleñas, la estructura de la propiedad del suelo agrícola se sustenta en los minifundios. Estos pequeños y medianos cosecheros históricamente no han tenido la necesidad de crear una estructura para comercializar el vino o las hortalizas, pues históricamente se han apoyado en formas populares ${ }^{20}$, vendiendo en el caso del vino, la uva a granel a las bodegas o haciendo su propio vino y vendiéndolo en casas de comida, más o menos improvisadas, instaladas en un cuarto, salón o patio de sus casas. Estos establecimientos, que en Tenerife se conocen como guachinches ${ }^{21}$, en esta Isla generan un significado volumen de renta ${ }^{22}$, constituyendo un auténtico subsector económico informal.

Estas formas de venta fueron soluciones válidas para dar salida a producciones modestas de vino, fruta o verdura. Ahora bien, la expansión de la actividad agraria y la necesidad imperiosa de obtener un beneficio, en el contexto de la crisis económica actual, ha disparado la producción y con ella la capacidad del sistema para asimilar de forma tradicional la producción.

Por su naturaleza, la cifra real de guachinches que actualmente existen en Tenerife es una incógnita. El Cabildo Insular calcula que en la Isla existen entre 500 y 1.000 establecimientos, que obviamente no coinciden todos abiertos a la vez, una rotación que hace muy difícil precisar cuántos están en funcionamiento en cada momento y lugar ${ }^{23}$.

19 Más del 60 por ciento de los cosecheros que siguen activos en La Palma son pensionistas, éstos siguen acudiendo a sus fincas sin ningún problema, pues no pierden su prestación siempre que el beneficio que genere su producción no supere el salario mínimo interprofesional (El Día, 14/10/2011, p. 38). Ahora bien, la administración sospecha que existe fraude fiscal y laboral en la actividad, camuflado como ayudas esporádicas y remuneradas a estos agricultores jubilados. Así se ha manifestado recientemente al realizarse inspecciones intensas en las explotaciones plataneras. Uno de los afectados, sorprendido por los inspectores mientras regaba sus plátanos, nos informa de las características de la finca así como de la forma de trabajo. «Ni siquiera me di cuenta al principio a lo que venían. Nuestra pequeña finca la hemos trabajado siempre para sacar algo más de dinero y yo no puedo pagar una multa, si es que al final me la ponen. Mi sobrino me ayuda en los plátanos de vez en cuando y no creí que eso fuera un delito» (Diario de Avisos, 6/10/2011, p. 42). En el trabajo de campo realizado en La Palma hemos constatado muchos ejemplos de este tipo.

20 El peso del cooperativismo agrario en producciones para el abastecimiento del mercado interior de frutas y verduras es modesto y sujeto a consecutivos fracasos. Las razones se deben a las peculiaridades de esta agricultura ya descritas en su esfera productiva y comercializadora, pero, además, a la reiterativa y efímera forma de constituir cooperativas agrarias, esto es, nacidas descapitalizadas económica y técnicamente, muy dependientes de subvenciones públicas y los controles políticos y con opacidad jurídica, económica y contable. Un ejemplo de esta situación es la Cooperativa de Benijos (La Orotava, Tenerife), una de las mayores cooperativas de papas de Canarias, actualmente en crisis.

21 Una disposición aprobada por el Consejo de Gobierno del Cabildo de Tenerife en octubre de 2009 contemplaba que el guachinche tenía la consideración de actividad comercializadora de vino, que permita al agricultor obtener una renta complementaria a su tarea agrícola.

22 Destacando los municipios de La Matanza, donde más del 50 por ciento de la superficie de cultivos corresponde a la viña y La Orotava (Tenerife).

23 Se habla que la crisis económica ha suscitado una auténtica explosión de guachinches: «con la crisis económica, el número de este tipo de casas de comidas ha aumentado en los dos últimos años hasta el millar y muchos de ellos se exceden en sus funciones, sirviendo otros vinos y bebidas, así como una mayor diversidad de platos» (La Opinión de Tenerife, 8/04/2011, p. 13). 
Son muchas las voces que claman por poner coto a lo que consideran un intrusismo profesional, restauración ilegal que favorece la economía sumergida y situaciones de fraude a los consumidores ${ }^{24}$. Distintos colectivos, especialmente los dedicados a la restauración y la viticultura, solicitan establecer un marco regulatorio a la actividad, así como una reducción del número de guachinches en funcionamiento ${ }^{25}$.

Por su parte, los ayuntamientos con más guachinches abiertos en su municipio no esconden que cerrarlos causaría graves problemas sociales, pues hay muchas familias que logran su único sustento gracias a esta actividad irregular.

Otro de los indicadores del aumento de la actividad agrícola, como consecuencia de la crisis, y de los inconvenientes de su comercialización es la proliferación de la venta ambulante de productos agrícolas. La crisis ha propiciado que la comercialización informal aumente considerablemente en el sector primario del Archipiélago. Ya hemos comentado las razones por la que son pocos los pequeños agricultores que acceden a modelos de venta directa en el mercado local. Muy pocos acuden a los mercadillos o mercados del agricultor municipales, venden a operadores comerciales o son cooperativistas. Mayormente, el pequeño agricultor canario encontró salida a sus producciones a través de vías alternativas, como la del gangochero, como tradicionalmente se denomina en Canarias al intermediario que compra los productos del campo directamente al agricultor para venderlos luego a los consumidores o al comercio. Pero de esta comercialización tradicional se ha pasado, buscando mejores márgenes, a la venta directa o ambulante.

El presidente de Asociación de Agricultores y Ganaderos de Canarias (ASAGA), Henry Sicilia, destacaba cómo había proliferado la venta ambulante de productos agrícolas y cómo cada vez se contabilizaban menos licencias de comercio ambulante y mercadillos en el Archipiélago, sin precisar la cantidad. Un ejemplo más del paso de esta actividad comercial minorista de alimentos a la economía sumergida.

Sicilia recalcaba que «sobre todo en Tenerife ha comenzado a resurgir la figura del gangochero, que no causa un daño alarmante, pero evidentemente puede repercutir en el sector agrícola ya que no solo va vendiendo sus productos directamente al consumidor, sino que también los va ofreciendo a pequeñas tiendas o cadenas de distribución y es en ese instante cuando puede convertirse en algo pernicioso».

Sicilia argumentó que es comprensible que ante la coyuntura actual «estén volviendo al campo muchas personas que en su día abandonaron la agricultura por el turismo, el transporte o la construcción o que haya gente que recupere la finca de sus padres o abuelos para ponerla en producción». Sin embargo, aclara que «todo lo que se destine al autoconsumo es

24 El consejero de Agricultura del Cabildo Insular José Joaquín Bethencourt indicó que «somos conscientes de que se está vendiendo mucho vino de fuera haciéndolo pasar por un caldo de la Isla, utilizando una figura de gran tradición como son los guachinches». En este sentido, dijo «un guachinche debe seguir siendo lo que ha sido siempre, un establecimiento donde un cosechero de uva tiene la oportunidad de ofrecer el vino, exclusivamente derivado de su cosecha a los consumidores» (Diario de Avisos, 8/04/2011, p. 8).

25 El secretario de la Asociación de Viticultores de Tenerife (ASVITEN), Valerio García, preveía el cierre de más del 20 por ciento de los guachinches de la Isla si se aplicaba el decreto regulador impulsado por el Gobierno de Canarias. «Se va a quedar mucha gente fuera. Dejarán de ser guachinches los que no sean de viticultores. El que no lo sea, que abra un restaurante o se dedique a otra cosa. El problema es para los que abren todo el año, que estaban ilegales y no tributaban ni pagaban a la Seguridad Social. La barra libre se va a acabar», dijo García (La Opinión de Tenerife, 20/06/2013, p. 14). 
lícito, pero lo que vaya a ser comercializado hay que hacerlo de manera organizada». Por tanto, aseveró: «Estamos intentando transmitir a los que se están incorporando a la agricultura por esta situación de crisis que no se pueden convertir en intrusos en el sector; que no podemos dar un paso atrás y que las calles se llenen de camionetas vendiendo papas con un altavoz».

En una evidente y clara defensa de la intermediación vía cooperativa, cada vez más discutida en las Islas por el cierre de muchas de estas entidades asociativas, sostenía: «No estoy de acuerdo con que se haga una persecución a alguien que se está buscando la vida», aunque enfatizaba que «esta práctica no es más que pan para hoy y hambre para mañana». Así pues, abogaba por que «este colectivo se ponga en contacto con la cooperativa más cercana para que se les asesore tanto a nivel técnico como fitosanitario y que se integren en el sector primario» (El Día, 24/08/2009, p. 24).

\section{CANALIZACIÓN INSTITUCIONAL DE LA VUELTA AL CAMPO: BANCOS DE TIERRAS Y HUERTOS URBANOS}

El hecho de que la agricultura se haya convertido en una alternativa al paro en estos momentos de crisis económica ha hecho variar la desconsideración que las instituciones canarias habían tenido hacia la actividad primaria de subsistencia. La Administración ha canalizado este retorno a la actividad agraria a través de dos formas: los bancos de tierras y los huertos urbanos.

Los bancos de tierra pretenden superar uno de los condicionantes para el desarrollo agrario dentro de la esfera de la producción, el que se refiere a la enorme dificultad para conseguir un terreno donde cultivar. Una tarea que aparentemente entraría en contradicción con la gran cantidad de tierras que, como hemos comentado, se encuentran abandonadas en Canarias.

Ahora bien, a pesar de la importante cantidad de tierras abandonadas, es difícil conseguir tierras para plantar. Comprar es imposible, por la coyuntura económica y el perfil sociolaboral de los nuevos trabajadores del campo. Además, los precios están muy por encima de la oferta objetiva como terrenos rústicos para actividades agrarias, pues los propietarios mantienen expectativas de venta a personas y sociedades ajenas al mundo agrario (extranjeros, empresarios de alojamiento rural, urbanizadores $)^{26}$. Anulada la posibilidad de compra, la única opción posible para futuros agricultores sin tierras es el arrendamiento.

Esta fórmula tampoco es fácil. La prospección llevada a cabo por la COAG nos señala algunas de las relaciones arrendatario y arrendador en el contexto actual (las referencias entre comillas son extractos literales de la entrevistas recogidas en este estudio). Señala la COAG cómo a menudo muchos propietarios quieren sacar rentas desproporcionadas por sus tierras y, si no es así, prefieren no arrendarlas y dejarlas abandonadas: «Para sacarle cuatro perras y que me la destrocen, mejor la dejo ahí quietita». El arrendamiento se dificulta porque el propietario no tiene la confianza suficiente de que el arrendatario vaya a

26 Estas expectativas hacen que Canarias presente el precio medio de la tierra más elevado del Estado: 61.814 euros por hectárea. Si lo analizamos por cultivos: el precio medio de tierras de labor en secano es de 35.585 euros por hectárea, de tierras de labor en regadío es de 85.000 euros por hectárea y el precio medio del viñedo es de 88.086 euros por hectárea. (Encuesta de Precios de la Tierra 2012. Principales resultados. Julio 2013. Ministerio de Agricultura, Alimentación y Medio Ambiente. Gobierno de España). 
dejar la finca en condiciones adecuadas y sobre todo, de que vaya a irse a la finalización del contrato: «Yo no la arriendo, luego al tío no lo sacas de ahí en la vida». También, muchos propietarios, por la posibilidad de vender, no arriendan, piensan que tener una finca arrendada puede dificultar una posible operación de venta o que no pueda vender por tener el terreno bajo un contrato de arrendamiento. Otros propietarios sólo arriendan si este trato se realiza sin contrato, de forma que puedan «echar» al trabajador en cualquier momento. En otros casos, los propietarios se acercan a este sistema aprovechando la demanda y para aprovechar la oportunidad de obtener rendimientos de tierras prácticamente improductivas. «Voy a poner la finca mala de abajo en el banco de tierras ese a ver si me pagan bien y saco un buen dinerito de ahí» (COAG, s.f.:4). «Los propietarios siguen teniendo altas pretensiones respecto a su tierra, creen que ganan a un medianero» (Entrevista 1. La Laguna, 2013).

Los bancos de tierras en Canarias son entidades municipales e insulares que pretenden facilitar los procesos de arrendamiento de tierras. Es una idea dirigida a recuperar el cultivo en áreas agrícolas abandonadas o que sus propietarios no pueden atender, propiciando el contacto entre personas interesadas en cultivar terrenos, pero que carecen de ellos, con propietarios agrícolas que sí los tienen pero no los cultivan ${ }^{27}$. De ahí que se considere como un banco, «hay quien viene a pedir tierra y quien la ingresa» (Diario de Avisos, 15/07/2011, p. 10), siendo la función del banco enlazar propietarios de los terrenos con potenciales agricultores.

Este servicio trata de crear, de una parte, una base de datos pública integrada por propietarios, en la que se enumeran una serie de características de sus parcelas: disponibilidad de agua, tipo de suelo, etc. Por otra parte, se elabora un inventario de interesados en ponerlas en cultivo, señalando qué cultivos quieren desarrollar y sus necesidades de superficie, tipos de suelo y calidad de agua, etc. «Si la demanda y la oferta coinciden se les ponen en contacto, para que entre ellos acuerden el posible sistema de gestión» (Canarias 7, 20/03/2011, p. 48).

Sobre el sistema de gestión, hay bancos que lo dejan en una simple recomendación de acogerse a la Ley de Arrendamientos (Banco de Tierras de Breña Alta-La Palma). Mientras que en otras, como es el caso del Banco de Tierras del Cabildo de Lanzarote, se obliga al propietario y al productor al cumplimiento de unas condiciones pactadas, indicando que las tierras deben ser arrendadas por un periodo de tiempo de 5 años como máximo, aportando el Cabildo el contrato de arrendamiento conforme a lo dispuesto en la Ley 26/2005.

Siguiendo con el caso de Lanzarote, uno de los más completos, las partes deben cumplir todas las condiciones expuestas en el contrato establecido y solo tendrán potestad de decidir el acuerdo económico del arrendamiento, que podrá ser mediante una cuantía económica o según lo convenido entre ambas partes, indicando el productor en el contrato el tipo de cultivos al que destinará el terreno ${ }^{28}$.

La demanda de nuevos agricultores en los bancos de tierras ha sido alta, no así la oferta y la calidad de esta. En tan sólo un mes, el Banco de Tierras de Lanzarote registró un total

27 Destacar que, a diferencia de otras experiencias estatales, no hemos encontrado en Canarias ningún banco de tierras que haya incorporado el suelo público en abandono.

28 «Hay quien pide dinero a cambio, quien pide una parte de la cosecha y también hay personas que no quieren nada y se conforman con ver sus tierras de nuevo sembradas» (Diario de Avisos, 15/07/2011, p. 29). 
de 200 peticiones de interesados en alquilar una parcela abandonada y 50 propietarios que deseaban ofertar tierras agrícolas de distinta calidad (Canarias 7, 8/06/2013, p. 48). Esta situación se vincula a la alta tasa de paro y al interés de muchos en situación de desempleo de producir alimentos para su autoabastecimiento.

El Banco de Tierras de Mazo (La Palma) captó 63 personas en el primer año, 20 propietarios y 43 demandantes (Diario de Avisos, 28/08/2012, p. 39), coincidiendo en las mismas razones vinculadas a la crisis. Lo mismo pasa en otros municipios. Así, el Banco de Tierras de la Denominación de Origen Vinos de La Palma señalaba que las causas que generaban el interés por arrendar terrenos de viñedos eran: «las necesidades económicas en las que se encuentran muchas personas, motivadas por la crisis, pérdida de ingresos por pérdida de empleos, la necesidad de ampliar sus explotaciones vitícolas al objeto de hacerlas más competitivas y el deseo creciente de muchas personas de producir para autoconsumo, alimentos más sanos y ecológicos» (canariasahora, 2013). En términos semejantes se expresaban otros municipios palmeros, como Breña Alta y Santa Cruz, en la isla de La Palma.

La otra modalidad de canalización del auge, por necesidad, de la actividad agrícola son los huertos urbanos. Las principales ciudades canarias contenían, hasta periodos recientes, áreas internas y próximas donde la actividad agraria era su función principal. Estos espacios sufrieron la presión demográfica que sobre las ciudades canarias generó el cambio de modelo económico suscitado con posterioridad a la década de los años sesenta. Además del cambio masivo de la actividad primaria por los servicios, se produjo un insistente proceso especulativo inmobiliario sobre los espacios agrícolas integrados en las áreas urbanas y periurbanas. Ambos aspectos dejaron la función agraria como una actividad productiva marginal dentro y en las proximidades de las ciudades canarias $^{29}$.

A partir de mediados de los noventa, se retoma la actividad agraria en el espacio urbano en relación con la idea del consumo de alimentos de calidad y la preocupación por la agricultura sostenible. Aparecen entonces los denominados huertos urbanos, una propuesta encaminada a revitalizar áreas degradadas y espacios residuales dentro de los entornos urbanos, que persigue, para una población que tiene sus demandas primarias cubiertas, la transformación de los solares en huertas con un fin educativo, paisajístico, ambiental o de ocio.

Alejados de su función productiva, los primeros huertos urbanos en Canarias aparecen en Las Palmas de Gran Canaria como apéndices de proyectos de Educación Ambiental y vinculados al Plan de Huertos Escolares. Es el caso del huerto de Salto del Negro, pionero entre los existentes (1999), que pasó de un cuidado exclusivamente estival (cuando no había colegio) por los vecinos, a huerto urbano del barrio llevado definitivamente por los padres de los niños. Semejante al anterior fue el huerto de Siete Palmas (2009), que también pasó de huerto escolar a estar en manos de los miembros del AMPA del Colegio Público una vez terminada esta iniciativa escolar.

Luego vendrían otros huertos cuyo objetivo fundamental era servir de apoyo a «programas de intervención educadora y social». Es el caso del huerto de El Polvorín (Las Palmas de Gran Canaria), situado en un barrio en el que se registra un alto índice de desempleo y

29 En determinadas localizaciones y perseguidos por las autoridades municipales que los acusaban de enclaves chabolistas, se mantuvieron pequeños huertos de recreo (muy pocos), de ayuda a la subsistencia, así como parcelas de usos múltiples, donde lo agrícola convivía con la ganadería, el reciclaje y la autoconstrucción (legal e ilegal). 
marginalidad, y donde el huerto se planteó inicialmente como una forma de socialización, entretenimiento y recientemente se ha ampliado a una función de mantenimiento (en precario) de la economía familiar ${ }^{30}$. A este, ya más recientemente, se le unieron otros en Gran Canaria, como la Finca del Pambaso, Pino Apolinario, en La Mayordomía, en El Lasso, etc.; y en otras islas: el huerto urbano de El Sobradillo, en Tenerife, o el de Puerto del Rosario, en Fuerteventura, entre otros, con el objetivo de fomentar el ocio y la subsistencia.

Las normas de funcionamiento de todos los huertos urbanos son similares. Se trata de huertos tradicionales integrados dentro del paisaje urbano del vecindario, en el que los vecinos, a través de las asociaciones, solicitan su instalación en terrenos cedidos por ellos mismos o municipales. El cuidado corre a cargo de los vecinos, que se comprometen por escrito a cultivarlos. A cambio, el Ayuntamiento les ofrece el material y en ocasiones el asesoramiento de un profesional. Los frutos deben ser consumidos por sus productores o cedidos a organizaciones sociales o a bancos de alimentos, pero no podrán ser vendidos ${ }^{31}$.

\section{CONCLUSIONES}

Abandonada a un futuro incierto, sin políticas de apoyo a la producción de alimentos, en las últimas décadas la agricultura de subsistencia en Canarias ha reducido su protagonismo económico, laboral y espacial. Un proceso que es resultado de un cúmulo de circunstancias entre las que destaca una progresiva pérdida de ingresos y rentas, inducidas por las enormes diferencias existentes entre los precios pagados por los consumidores y los recibidos por los agricultores, una apuesta institucional manifiesta por abaratar importaciones antes que fomentar la oferta local agropecuaria y una notable presión urbanística sobre el suelo rústico, que tienta crecientemente al agricultor-propietario a convertir su finca en un apéndice más del espacio urbano.

30 «Llevo cinco años en el paro, y como yo hay mucha gente en el barrio», explica Ulises Barrios, que junto a su mujer, Merci Artiles, también desempleada desde hace cuatro años, ayuda en el huerto que le adjudicaron a su suegra. «He trabajado en la construcción y en otros muchos empleos, además de que no tendría problema para moverme a trabajar fuera de la isla porque ya he trabajado en Tenerife, señala. Pero dice que el panorama es oscuro y el trabajo en la tierra «me permite estar distraído, además de que es una ayuda para la casa». Añade que lo que su mujer y él cultivan beneficia también a algún que otro vecino. «Cuando recogemos lo que cultivamos lo repartimos», explica Merci, «y es que hemos llegado a coger más de 20 kilos de calabacines», señala satisfecha. «Además, siempre hay algún vecino que viene a pedir unas acelgas o una manojo de hierbahuerto, y se lo damos sin ningún problema», apunta Ulises. Merci entiende que «si para algo ha servido la crisis es para que todos nos ayudemos un poco, porque de otra manera no vamos a salir de esta». De la misma opinión es Nicolás Álamo, que cuida de una de las parcelas del huerto y tiene una prestación por desempleo a punto de extinguirse. «También nos ayudamos entre los que cultivamos los huertos, porque si hoy te hace falta a ti una de mis cebollas te la doy, porque sé que mañana serás tú el que me ayude con cualquier otra cosa», indica. Aclaran que, lamentablemente, estos huertos no solucionan la necesidad de ninguna familia, pues su producción es limitada. Pero dicen que lo que la tierra les da, les permite no solo ayudar en sus casas, sino echar una mano a sus familiares y algunos vecinos, sobre todo los mayores (Canarias 7, 24/12/2012, p. 4).

31 «B) Prohibición de subarriendo y de comercialización de los productos obtenidos. La explotación de los huertos urbanos se autoriza con una finalidad de ocio, estando prohibido expresamente su arriendo a terceras personas, así como la comercialización de los productos cultivados, que sólo serán destinados al autoconsumo o, en su caso, a la donación. Sólo será factible el intercambio y/o trueque entre los usuarios del huerto» (AYUNTAMIENTO DE SANTA CRUZ DE TENERIFE, 2013). 
En esta coyuntura acontece, de forma brusca, la crisis estructural vigente, que acabó de un plumazo con la aparente inagotable capacidad del binomio construcción-servicios para generar salarios altos y demandas laborales.

Empujados por la crisis y abandonados por lo que habían sido las palancas de la economía canaria, muchos parados acuden o intensifican su contacto con las actividades agrarias de subsistencia. Y lo hacen, aquellos que poseen tierras, en un primer momento exclusivamente como estrategia de autoconsumo o de complemento a los mecanismos de protección social (subsidios de paro o jubilaciones). Luego, empeoradas sus condiciones económicas por intensificación de la crisis, comienzan a producir excedentes y a aumentar el tamaño de sus explotaciones y la cantidad de sus producciones, pasando entonces de la subsistencia a la comercialización de remanentes en un mercado local, con el objetivo de obtener una renta necesaria para compensar las pérdidas producidas por los recortes en pensiones y subsidios.

Los excedentes producidos se comercializan en parte fuera de los mercados regulares, como un renglón más de la economía sumergida. En esta situación, establecimientos como los guachinches, cuya función y actividad era comercializar el vino y los productos del campo de producción propia en el salón de su casa, se han desbordado en número y, en islas como Tenerife, presentan casi una continua oferta en algunas localizaciones (norte de la Isla). Otro ejemplo es la proliferación de la venta ambulante, en las cunetas o casa por casa sin licencia, indicador claro del crecimiento de la actividad y el papel creciente que esta modalidad comercial «en negro» tiene entre una población que busca alimentos más baratos.

La forma de entrada en la actividad agrícola para los parados sin tierras, eliminada obviamente la posibilidad de compra por razones de su condición sociolaboral, es el arrendamiento. Este se lleva a cabo de manera individual o adscribiéndose a fórmulas como los bancos de tierras.

La demanda de tierras ha estimulado a las administraciones públicas, tras años de dar la espalda al problema del abandono agrario, a crear los bancos de tierra. Una propuesta de intermediación entre propietarios de fincas y demandantes de trabajo en el campo, para que estos últimos arrienden sus tierras. El resultado no ha sido negativo, pero en la mayoría de los casos la demanda ha superado a la oferta. Además, los bancos de tierra, al influir exclusivamente en la esfera de la producción, no han resuelto el grave problema de la comercialización y la lucha contra los importadores y los bajos precios, más allá de alguna solución parcial vía mercados del agricultor o de productos ecológicos.

La otra modalidad implementada para canalizar la demanda agraria han sido los huertos urbanos para cultivos de subsistencia. Una solución peor que los bancos de tierras, pues a las familias no les vale solo con producir alimentos para comer. Las necesidades familiares son mucho más amplias que el sustento, aun cuando este sea sumamente importante. Por tanto, un huerto urbano en el que está prohibido vender, esto en caso de que produzca excedentes, pues las parcelas son extraordinariamente pequeñas, aparece más como una afición, una satisfacción por trabajar en él, pero no una real alternativa a la crisis.

Por último, señalar que, con esta crisis tan profunda como la que sufrimos, el sector primario en Canarias ha pasado de ser una actividad poco atractiva y en continua pérdida de efectivos, a ser una opción al alza para la subsistencia. Esta reacción contradice el discurso dominante de la Administración, que ha defendido durante décadas los espacios agrarios de subsistencia no en su sentido estricto de productor de alimentos, sino como un espacio «natu- 
ral» o de ocio, aun cuando en muchos de ellos fuera la escasa actividad agraria existente quien definiera su supuesta naturalidad o su atractivo turístico. En este sentido, se podría decir que la crisis ha destacado, por necesidad vital, la importancia de la producción de alimentos frente a discursos ambientales, sostenibles y multifuncionales.

Del mismo modo, la crisis, ha puesto en primer plano las gravísimas dificultades existentes de la actividad agraria para el mercado interior en Canarias. En la esfera de la producción, estaría el alto precio del suelo agrícola por competencia libre con otros usos, dificultades para el arrendamiento de tierras y aumento de los costes: agua, semillas, abonos. Mientras que en la esfera de la comercialización tendríamos la entrada masiva de alimentos importados a bajo precio, la inestabilidad en los ingresos y las rentas reducidas por una enorme diferencia entre los precios pagados por los consumidores y los recibidos por el agricultor. Toda una serie de aspectos que reclaman, una urgente protección y gestión del espacio agrario de las islas, como espacio productivo de alimentos. Se debe apostar por propiciar el acceso al agua y a la tierra, pública y privada, a aquellos que hoy en día la demandan, limitar la especulación con medidas drásticas de protección al suelo agrario, ayudar a las estructuras agrarias, disminuir los excesos fiscales y burocráticos que deben afrontar los agricultores, limitar las importaciones o gravarlas y garantizar precios de referencia a las producciones agrícolas de subsistencia.

\section{BIBLIOGRAFÍA}

ACIPMAGA. ASOCIACIÓN CANARIA INDEPENDIENTE DE PEQUEÑOS Y MEDIANOS AGRICULTORES Y GANADEROS (2009): Agri-cultura. 262 págs. Inédito.

ACPCACE (2010): «Análisis de Costes, Precios y Competitividad en la Agricultura Canaria de Exportación». Proyecto de Investigación I+D+I. Investigador principal: José Juan Cáceres Hernández., Departamento de Economía de las Instituciones, Estadística Económica y Econometría - Departamento de Economía Financiera y Contabilidad. Universidad de La Laguna. 2009-2011.

http://jggomez.eu/G\%20invescost/01estudios/Acpcace/Acpcace.html. Consultado el 13 de marzo de 2013.

AYUNTAMIENTO DE SANTA CRUZ DE TENERIFE (2013): Bases reguladoras que han de regir la adjudicación gratuita de 20 parcelas del huerto urbano denominado «el sobradillo», mediante autorización demanial de uso. Ayuntamiento de Santa Cruz de Tenerife. http://www.santacruzdetenerife.es/uploads/media/BASES_20130405.pdf. Consultado el $13 / 09 / 2013$.

AYUNTAMIENTO DE LAS PALMAS DE GRAN CANARIA (2011): Red municipal de huertos urbanos. Las Palmas de Gran Canaria. Ayuntamiento de Las Palmas de Gran Canaria. http://www.laspalmasgc.es/views/Servicios/MedioAmbiente/Huertos\%20Urbanos/Proyecto.pdf. Consultado el 13/09/2013.

AYUNTAMIENTO DE LAS PALMAS DE GRAN CANARIA (2013): RESOLUCIÓN del Concejal de Gobierno del Área de Movilidad Ciudadana y Medio Ambiente, por la que se aprueba las Normas de Uso y Gestión y el Acta de Autorización del Uso de las parcelas de los Huertos Urbanos del Término Municipal de Las Palmas de Gran Canaria. Ayuntamiento de Las Palmas de Gran Canaria. 
http://www.laspalmasgc.es/views/Servicios/MedioAmbiente/Huertos\%20Urbanos/130405\%20Normas\%20Uso\%20Huertos\%20Urbanos.pdf. Consultado el $13 / 09 / 2013$.

COAG (2010): Empleo Agrario en 2010. Informes y Servicios Técnicos. 5/04/2010. http://www.coag.org/rep_ficheros_web/dca5ad7949faa03257d1a92432251db5.pdf Consultado el 4/04/2012.

COAG CANARIAS (s.f.): Metodología para la puesta en marcha de bancos de tierra funcionales en la isla.

http://www.coag.org/rep_ficheros_web/84aa5b56f02eaf005546e8dddde50df6.pdf. Consultado el 7/09/2013.

GARCÍA RODRÍGUEZ, J.L. y PESTANA PÉREZ, G. (2010). Las Medianías. Agricultura paisaje y desarrollo rural en Canarias. La Laguna, Asociación de Geógrafos Españoles.

GARCÍA RODRÍGUEZ, J.L. (2009): «Desarrollo moderno de los territorios rurales». En SIMANCAS CRUZ, M. (Ed.) El impacto de la crisis en la economía canaria. Volumen I. San Cristóbal de La Laguna, Real Sociedad Económica de Amigos del País.

GARCÍA RODRÍGUEZ, J.L. (Ed.) (2002): Identidad y desarrollo local. Perspectivas de la globalización desde las Islas Canarias. Santa Cruz de La Palma, Excmo. Cabildo Insular de La Palma.

GODENAU, D.; SUÁREZ SOSA, S.J. y FEBLES RAMÍREZ, M. (2009): Análisis de los resultados de la Encuesta Rural Tenerife 2007.

http://www.agrocabildo.org/publica/Publicaciones/enru_232_L_ana_res_Enc_Rur.pdf. Consultado el 23/09/2013. Consultado el 23/09/2013.

HERNÁNDEZ HERNÁNDEZ, J. y RODRÍGUEZ BRITO, W. (1992): «Las transformaciones recientes en el sector agrario en Canarias», en RODRÍGUEZ MARTÍN J. A. y HERNÁNDEZ HERNÁNDEZ, J. Geografía de Canarias 1985-1991, Vol. 7, Cap.6. Santa Cruz de Tenerife, Interinsular Canaria, págs.124-156.

INMOCAMARAS (2010): Análisis de contexto de Canarias (Multisectorial). Las Palmas de Gran Canaria, Unión Europea, Fondo Social Europeo - Agencia Canaria de Investigación, Innovación y Sociedad de la Información, Gobierno de Canarias - Cámaras Canarias.

http://www.innocamaras.org/metaspace/file/46992.pdf Consultado el 5/03/2013.

OBECAN (2013): Informe Paro y Contratos. Febrero 2013. Las Palmas de Gran Canaria, Observatorio Canario de Empleo y la Formación Profesional. Gobierno de Canarias. http://www3 .gobiernodecanarias .org/empleo/portal/observatorio/index.php?option=com_ content $\&$ view $=$ article $\&$ id $=263 \&$ Itemid $=238$ Consultado el 12/04/2013.

PERDOMO MOLINA, A.C. y HERNÁNDEZ ABREU, J.M. (2003): «El desarrollo rural en Canarias desde la perspectiva institucional. Objetos e instrumentos establecidos en el Cabildo Insular de Tenerife». En GARCÍA RODRÍGUEZ, J.L. (Ed): Desarrollo Rural en territorios insulares. Especial referencia a las Islas Canarias. Santa Cruz de La Palma, Centro de Cooperación y Desarrollo Territorial de la Universidad de Oviedo. Excmo. Cabildo Insular de La Palma, págs.83-102.

RODRÍGUEZ BRITO, W. (1986): La agricultura de exportación en Canarias (19401980). Santa Cruz de Tenerife, Consejería de Agricultura, Ganadería y Pesca. Gobierno de Canarias. 
RODRÍGUEZ BRITO, W. (1988): «Cultivos básicos de exportación». En AFONSO, L. (Ed.): Geografía de Canarias. Aspectos sectoriales. Tomo 3 capítulo IV, Santa Cruz de Tenerife, Interinsular Canaria, págs.97-138.

SEGRELLES SERRANO, J.A. y VÁSQUEZ SÁNCHEZ (Coord.) (2012): Multifuncionalidad rural y nueva ruralidad. La experiencia europea y la potencialidad de Colombia. Madrid, Ministerio de Agricultura, Alimentación y Medio Ambiente. Gobierno de España.

\section{PÁGINAS WEB}

http://www.agrolanzarote.com/servicios/banco-tierras

http://www.cabildofuer.es/

http://www.canariasahora.es/

http://www.villademazo.es/banco_tierras.pdf

http://www.lavozdelapalma.com/2011/10/25/http://www.santacruzdetenerife.es/serviciosmunicipales/medioambiente-y-sanidad/huertos-urbanos/

\section{HEMEROTECA}

Canarias 7. Las Palmas de Gran Canaria.

Diario de Avisos. Santa Cruz de Tenerife.

El Día. Santa Cruz de Tenerife.

La Opinión de Tenerife. Santa Cruz de Tenerife.

La Provincia. Las Palmas de Gran Canaria.

La Tribuna de Canarias. Santa Cruz de Tenerife.

La Voz de Tenerife. Periódico Digital.

Lancelot. Arrecife Lanzarote.

Mundo Rural. Santa Cruz de Tenerife. 
